\title{
Faktor-Faktor yang Berhubungan dengan Kejadian Diabetes Mellitus di UPTD Diabetes Center Kota Ternate Tahun 2018
}

\author{
Helena Wadja1 ${ }^{1}$ Hamidah Rahman², Nani Supriyatni ${ }^{2 \bowtie}$ \\ ${ }^{1}$ Mahasiswa Peminatan Epidemiologi Fakultas Ilmu Kesehatan, Universitas Muhammadiyah Maluku Utara. Ternate. \\ Indonesia, \\ Email : helenawadja1994@gmail.com \\ ${ }^{2}$ Staf Pengajar Fakultas Ilmu Kesehatan, Universitas Muhammadiyah Maluku Utara. Ternate. Indonesia, \\ Email : naniskm@yahoo.com, hamidahr42@gmail.com

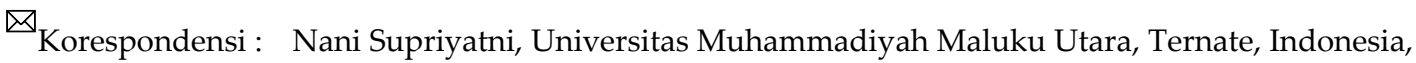 \\ Email : naniskm@yahoo.com
}

\begin{abstract}
ABSTRAK.
Diabetes adalah penyakit yang berlangsung lama atau kronis serta ditandai dengan kadar gula (glukosa) darah yang tinggi atau di atas nilai normal. Glukosa yang menumpuk di dalam darah akibat tidak diserap sel tubuh dengan baik dapat menimbulkan berbagai gangguan organ tubuh. Diabetes melitus (DM) menjadi ancaman serius bagi kesehatan manusia pada abad ke21. Jumlah penderita DM mencapai 422 juta orang di dunia pada tahun 2014. Sebagian besar dari penderita tersebut berada di negara berkembang. Indonesia sebagai salah satu negara berkembang memiliki jumlah penderita yang cukup tinggi. Tujuan penelitian ini adalah untuk mengetahui hubungan tingkat pengetahuan, tingkat stres, dan durasi tidur terhadap kejadian Diabetes Mellitus. Metode penelitian dengan menggunakan desain cross sectional study. Populasi dalam penelitian ini adalah pasien yang datang memeriksakan kadar gula darah di UPTD Diabetes Center Kota Ternate Tahun 2018. Jumlah sampel 95 orang yang diambil dengan cara accidental sampling. Hasil uji statistik dengan menggunakan uji chi square menunjukkan bahwa faktor-faktor yang berhubungan dengan penyakit Diabetes Mellitus adalah tingkat stres dengan $\mathrm{p}$-value $=0,037(<0,1)$ dan durasi tidur dengan $\mathrm{p}$-value $=0,025(<0,1)$, sedangkan yang tidak berhubungan adalah tingkat pengetahuan dengan $p$-value $=0,709(>0,1)$. Oleh karena itu, disarankan kepada petugas kesehatan lebih meningkkatkan lagi informasi kepada masyarakat tentang penyakit Diabetes Mellitus, agar masyarakat lebih tahu tentang penyakit Diabetes Mellitus.
\end{abstract}

\section{Keyword: Pengetahuan, Tingkat Stres, Durasi tidur, Diabetes Mellitus}

\section{PENDAHULUAN}

Kesehatan masyarakat adalah ilmu dan seni untuk mencegah penyakit, memperpanjang hidup, mempromosikan kesehatan dan efisiensi dengan menggerakan potensi seluruh masyarakat. Konsep kesehatan masyarakat berkaitan dengan perubahan perilaku sehat akan lebih terbentuk dan bertahan lama bila dilandasi kesadaran sendiri sehingga konsep upaya sehat dari, oleh dan untuk masyarakat sangat tepat diterapkan (Irianto, 2014).

Penyakit Tidak Menular (PTM) merupakan salah satu kelompok penyakit yang memberi beban kesehatan masyarakat tersendiri karena keberadaannya cukup prevalen, tersebar di seluruh dunia, menjadi penyebab utama kematian dan cukup sulit untuk dikendalikan. Perhatian terhadap PTM makin hari makin menigkat karena semakin menigkatnya frekuensi kejadiannya pada masyarakat. Peningkatan ini terutama terjadi pada diabetes, stroke dan hipertensi, oleh karena itu PTM semakin hari makin menjadi masalah utama kesehatan masyarakat (Bustan, 2015).

Menurut data World Health Organisation (WHO) tahun 2016, diabetes melitus (DM) menjadi ancaman serius bagi kesehatan manusia pada abad ke-21. Jumlah penderita DM mencapai 422 juta 
orang di dunia pada tahun 2014. Sebagian besar dari penderita tersebut berada di negara berkembang. Indonesia sebagai salah satu negara berkembang memiliki jumlah penderita yang cukup tinggi.

Penyakit diabetes mellitus dikenal juga dengan penyakit kencing manis atau kencing gula. Lebih kurang dua ribu tahun yang lalu, dua ahli kesehatan Yunani, yaitu Celcus dan Areteus, memberikan sebutan diabetes pada orang yang menderita banyak minum dan banyak kencing. Oleh karena itu, sampai saat ini penderita "banyak minum" dan "banyak kencing" tersebut dalam dunia kedokteran dikenal dengan istilah Diabetes Mellitus (DM). Diabetes mellitus tergolong penyakit tidak menular yang penderitanya tidak dapat secara otomatis mengendalikan tingkat gula (glukosa) dalam darahnya. Pada tubuh yang sehat, kelenjar pankreas melepas hormon insulin yang bertugas mengangkut gula melalui darah ke otot-otot dan jaringan lain untuk memasok energi (Irianto, 2014).

Pengetahuan tentang penyakit diabetes mellitus sangat penting karena tidak hanya untuk memahami penyakit tersebut tetapi pasien dapat menentukan langkah-langkah yang perlu diambil dalam rangka mengurangi beratnya penyakit. Dengan pengetahuan manusia dapat mengembangkan apa yang diketahui dan dapat mengatasi kebutuhan kelangsungan hidup (Conceicao dkk, 2011).

Faktor lain yang diduga sebagai faktor risiko DM adalah stres sebab tingkat stres tinggi akan mempengaruhi kadar gula darah dan metabolisme insulin. Jadi stres dapat menjadi pemicu diabetes. Secara psikologi akibat stress dapat terjadinya perubahan gaya hidup, gaya pola makan dengan cemilan mengandung kadar gula tinggi. Stres juga dapat terjadi karena pekerjaan hingga masalah keluarga. Stres tak hanya bisa berdampak bagi kondisi psikologis seseorang. Tanpa disadari stres berkepanjangan ternyata dapat memicu kadar gula darah naik, ketika stres akan merangsang hormon stres menjadi naik (Yunir Em, 2014).

Kekurangan tidur yang kronis dapat menyebabkan sejumlah efek yang tidak sehat terhadap tubuh. Penelitian telah membuktikan durasi tidur yang tidak cukup akan meningkatkan risiko obesitas dan penyakit kardiovaskular. Selain itu, kurangnya tidur dapat menyebabkan peningkatan kadar gula darah, yang salah satu penyebabnya adalah gangguan terhadap toleransi glukosa. Jika keadaan ini berlanjut dapat menyebabkan diabetes mellitus tipe 2 (Ariesiela dkk, 2014).

Prevalensi penyakit ini terus bertambah secara global. Data di Indonesia menyebutkan bahwa prevalensi DM menurut Riset Kesehatan Dasar (Riskesdas) tahun 2013 secara nasional adalah sebesar 6,9 \% meningkat dari tahun 2007 yang hanya sebesar 5.8\% dan menempatkan DM pada urutan ke-6 sebagai penyakit penyebab kematian terbanyak (Riskesdas, 2013).

Berdasarkan data yang diperoleh dari Dinas Kesehatan Kota Ternate pada tahun 2015 tercatat kasus diabetes mellitus dengan prevalensi 30,6\%, tahun 2016 dengan jumlah prevalensi 27,9\%, dan pada tahun 2017 prevalensi sebanyak 41,5\% (Dinas Kesehatan Kota Ternate 2017). Untuk yang diperoleh dari Unit Pelaksana Teknis Daerah (UPTD) Diabetes Center yaitu jumlah penderita diabetes mellitus pada tahun 2015 tercatat sebanyak 1.137, pada tahun 2016 terdapat kasus sebanyak 1.292 dan pada tahun 2017 sebanyak 1802 kasus ( Data UPTD Diabetes Center, tahun 2017).

Berdasarkan latar belakang di atas, maka peneliti ingin meneliti faktor-faktor yang berhubungan dengan kejadian diabetes mellitus yaitu dengan mengukur pengetahuan, tingkat stres dan durasi tidur di UPTD Diabetes Center Kota Ternate.

\section{Metodologi Penilitian}

Penelitian ini menggunakan jenis penelitian kuantitatif dengan pendekatan desain cross sectional study, penelitian ini dilaksanakan pada tanggal 19 Oktober 2018. Populasi dalam penelitian ini adalah seluruh pasien yang datang memeriksakan kadar gula darah di UPTD Diabetes Center Kota Ternate pada tahun 2018. Sampel adalah sebagian dari populasi yang merupakan perwakilan dari 
populasi. Besarnya sampel dalam penelitian ini adalah 95 orang atau responden dari 1802 populasi di UPTD Diabetes Center Kota Ternate.

\section{Hasil dan Pembahasan}

\subsection{Hasil}

\subsection{Analisis Univariat}

Tabel 1. Distribusi Frekuensi Kejadian Diabetes Mellitus Di UPTD Diabetes Center Kota Ternate Tahun 2018

\begin{tabular}{lcc}
\hline Status Responden & Jumlah & Persentase (\%) \\
\hline Menderita & 33 & 33,7 \\
Tidak Menderita & 62 & 66,3 \\
Total & 95 & $100 \%$ \\
\hline
\end{tabular}

Sumber : Data Primer Tahun 2018

Berdasarkan Tabel 2 diketahui bahwa sebanyak 33 orang (33,7\%) menderita diabetes sedangkan tidak menderita diabetes sebanyak 62 orang $(66,3 \%)$. Hal tersebut menunjukkan bahwa dari 95 responden yang diteliti terdapat tidak menderita diabetes mellitus lebih banyak dari pada yang menderita diabetes mellitus.

\subsection{Anallisis Bivariat}

Tabel 2. Hubungan Pengetahuan dengan Kejadian Diabetes Mellitus di UPTD Diabetes Center Kota Ternate Tahun 2018

\begin{tabular}{|c|c|c|c|c|c|c|c|}
\hline \multirow{3}{*}{$\begin{array}{c}\text { Tingkat } \\
\text { Pengetahuan }\end{array}$} & \multicolumn{4}{|c|}{ Status Responden } & & & \multirow[b]{2}{*}{ p-value } \\
\hline & \multicolumn{2}{|c|}{ Menderita } & \multicolumn{2}{|c|}{$\begin{array}{c}\text { Tidak } \\
\text { Menderita }\end{array}$} & \multicolumn{2}{|c|}{ Total } & \\
\hline & $\mathbf{n}$ & $\%$ & $\mathbf{n}$ & $\%$ & $\mathbf{N}$ & $\%$ & \\
\hline Baik & 17 & 32,1 & 36 & 67,9 & 53 & 100 & 0,709 \\
\hline Kurang & 15 & 35,7 & 27 & 64,3 & 42 & 100 & \\
\hline Total & 32 & 33,7 & 63 & 66,3 & 95 & 100 & \\
\hline
\end{tabular}

Sumber : Data Primer Tahun 2018

Berdasarkan Tabel 10 hasil analisis hubungan antara pengetahuan dengan kejadian diabetes mellitus diperoleh bahwa diantara 53 responden yang memiliki pengetahuan baik terdapat 17 responden $(32,1 \%)$ yang menderita diabetes mellitus, sedangkan diantara 42 responden yang memiliki pengetahuan yang kurang terdapat 15 responden $(35,7)$ yang menderita diabetes mellitus. Dari uji statistik diperoleh nilai $p$-value sebesar 0,709. Hal ini menunjukkan bahwa pada tingkat kemaknaan $10 \%$, tidak ada hubungan yang bermakna antara tingkat pengetahuan dengan kejadian diabetes mellitus.

Tabel 3. Hubungan Tingkat Stres dengan Kejadian Diabetes Mellitus di UPTD Diabetes Center Kota Ternate Tahun 2018

\begin{tabular}{|c|c|c|c|c|c|c|c|}
\hline \multirow{3}{*}{$\begin{array}{l}\text { Tingkat } \\
\text { Stres }\end{array}$} & \multicolumn{4}{|c|}{ Status Responden } & & & \multirow[b]{2}{*}{ p-value } \\
\hline & \multicolumn{2}{|c|}{ Menderita } & \multicolumn{2}{|c|}{$\begin{array}{c}\text { Tidak } \\
\text { Menderita }\end{array}$} & \multicolumn{2}{|c|}{ Total } & \\
\hline & $\mathbf{N}$ & $\%$ & $\mathbf{N}$ & $\%$ & $\mathbf{N}$ & $\%$ & \\
\hline Ringan & 2 & 18,2 & 9 & 81,8 & 11 & 100 & \\
\hline Sedang & 5 & 18,5 & 22 & 81,5 & 27 & 100 & 0,037 \\
\hline Berat & 25 & 43,9 & 32 & 56,1 & 57 & 100 & \\
\hline Total & 32 & 33,7 & 63 & 66,3 & 95 & 100 & \\
\hline
\end{tabular}


Berdasarkan tabel 11 hasil analisis hubungan antara tingkat stres dengan kejadian diabetes mellitus diperoleh bahwa diantara 11 responden yang memiliki tingkat stres ringan terdapat 2 responden $(18,2 \%)$ yang menderita diabetes mellitus dan diantara 27 responden yang memiliki tingkat stres sedang terdapat 5 responden $(18,5)$ yang menderita diabetes mellitus, sedangkan di antara 57 responden terdapat 25 responden $(43,9)$ yang menderita diabetes mellitus. Dari uji statistik diperole $p$-value sebesar $0,037<0,1$. Hal ini menunjukkan pada tingkat kemaknaan $10 \%$, artinya ada hubungan yang bermakna antara tingkat stres dengan kejadian diabetes mellitus.

Tabel 4. Hubungan Durasi Tidur dengan Kejadian Diabetes Mellitus di UPTD Diabetes Center Kota Ternate Tahun 2018

\begin{tabular}{|c|c|c|c|c|c|c|c|}
\hline \multirow{3}{*}{$\begin{array}{l}\text { Durasi } \\
\text { Tidur }\end{array}$} & \multicolumn{4}{|c|}{ Status Responden } & \multirow{2}{*}{\multicolumn{2}{|c|}{ Total }} & \multirow{3}{*}{$p$-value } \\
\hline & \multicolumn{2}{|c|}{ Menderita } & \multicolumn{2}{|c|}{$\begin{array}{c}\text { Tidak } \\
\text { Menderita }\end{array}$} & & & \\
\hline & $\mathbf{n}$ & $\%$ & $\mathbf{n}$ & $\%$ & $\mathbf{N}$ & $\%$ & \\
\hline Baik & 0 & 0,0 & 9 & 100,0 & 9 & 100 & 0,025 \\
\hline Buruk & 32 & 37,2 & 54 & 62,8 & 86 & 100 & \\
\hline Total & 32 & 33,7 & 63 & 66,3 & 95 & 100 & \\
\hline
\end{tabular}

Berdasarkan Tabel 4 hasil analisis hubungan antara durasi tidur dengan kejadian diabetes mellitus diperoleh bahwa diantara 9 responden yang memiliki durasi tidur baik tidak terdapat penderita yang mengalami durasi tidur baik $(0,0 \%)$, sedangkan diantara 86 responden yang memiliki durasi tidur buruk terdapat 32 responden $(37,2)$ yang menderita diabetes mellitus. Dari uji statistik diperoleh nilai $p$-value $0,025<0,1$. Hal ini menunjukkan pada tingkat kemaknaan $10 \%$, artinya ada hubungan yang bermakna antara durasi tidur dengan kejadian diabetes mellitus.

\subsection{Pembahasan}

\subsubsection{Gambaran Kejadian Diabetes Mellitus di UPTD Diabetes Center Kota Ternate.}

Diabetes mellitus merupakan salah satu dari Penyakit Tidak Menular yang menjadi masalah kesehatan masyarakat yang sering ditemukan di pelayanan kesehatan terhadap masyarakat. Diabetes mellitus adalah peningkatan kadar gula darah baik kadar gula darah sewaktu dan kadar gula darah puasa, dengan batas kadar gula darah sewaktu untuk yang tidak menderita diabetes $<110 \mathrm{mg} / \mathrm{dL}$ dan batas kadar gula darah sewaktu untuk yang menderita diabetes $>200 \mathrm{mg} / \mathrm{dL}$.

Berdasarkan penelitian ini bahwa dari 95 responden terdapat penderita diabetes mellitus sebanyak 33 orang $(33,7 \%)$ sedangkan yang tidak menderita diabetes mellitus sebanyak 62 orang $(66,3 \%)$ dengan demikian bahwa responden yang tidak menderita diabetes mellitus lebih banyak dibandingkan dengan penderita diabetes mellitus. Dan dalam penelitian ini terdapat responden perempuan atau ibu rumah tangga yang lebih berisiko terkena penyakit diabetes mellitus karena berdasarkan penelitian ini bahwa wanita yang berada di rumah setiap hari, aktivitas fisiknya relatif tidak sebanyak seperti pria yang bekerja.

Pengendalian utama yang akan dilakukan untuk menurunkan angka kejadian diabetes mellitus adalah dengan melakukan program gaya hidup sehat seperti, lebih memperdalam lagi pengetahuan tentang kejadian diabetes mellitus, kurangi tingkat stres terhadap diri kita dan menerapkan pola tidur yang baik agar dapat terhindar dari gejala-gejala kejadian diabetes mellitus. Untuk mengendalikan agar seseorang yang terdiagnosis diabetes mellitus diperlukan pengobatan maupun terapi diabetes mellitus agar mengurangi angka kejadian maupun kematian akibat dampak kelanjutan dari kadar gula darah yang tinggi. 


\subsubsection{Hubungan antara Tingkat Pengetahuan dengan Kejadian Diabetes Mellitus di UPTD Diabetes Center.}

Pengetahuan merupakan salah satu faktor yang sangat penting dalam pengendalian, pengobatan maupun pencegahan terhadap suatu penyakit seperti penyakit diabetes mellitus. Semakin tinggi pengetahuan masyarakat terhadap suatu penyakit semakin berkurang pula angka kejadian suatu penyakit. Yang artinya masyarakat dapat mengetahui bagaimana gejala, penyebab, pengobatan maupun pencegahan dari penyakit diabetes mellitus.

Berdasarkan hasil penelitian ini menunjukkan bahwa dari 53 responden yang memiliki pengetahuan baik terdapat sebanyak 17 responden $(32,1 \%)$ yang menderita diabetes mellitus sedangkan dari 42 responden yang memiliki pengetahuan kurang terdapat sebanyak 15 responden $(35,7 \%)$ yang menderita diabetes mellitus. Hasil uji statistik $p$-value 0,709 $>0,1$ sehingga $\mathrm{H}_{\mathrm{o}}$ diterima, yang berarti tidak ada hubungan yang bermakna antara tingkat pengetahuan dengan kejadian diabetes mellitus di UPTD Diabetes Center Kota Ternate.

Dengan demikian hubungan antara tingkat pengetahuan dengan kejadian diabetes mellitus maka $\mathrm{H}_{\mathrm{o}}$ diterima yang artinya tidak ada hubungannya atau pengetahuan baik lebih tinggi dari pada pengetahuan kurang terhadap kejadian penyakit diabetes mellitus, berdasarkan hasil penelitian ini dikarenakan ada faktor lain yang mempengaruhi yaitu sikap dan perilaku responden yang sudah mulai menerapkan pola hidup yang sehat seperti tidak lagi mengkonsumsi makanan yang mengandung banyak gula. Sedangkan untuk responden yang masih kurangnya pengetahuan terhadap kejadian diabetes mellitus dikarenakan bahwa berdasarkan penelitian ini terdapat responden yang masih belum mengetahui tentang penyakit diabetes mellitus dimulai dari gejala, penyebab dan komplikasi dari penyakit diabetes mellitus.

\subsubsection{Hubungan Tingkat Stres dengan Kejadian Diabetes Mellitus di UPTD Diabetes Center Kota Ternate}

Stres adalah respon tubuh yang tidak spesifik terhadap setiap kebutuhan tubuh yang terganggu. Stres adalah suatu fenomena universal yang terjadi dalam kehidupan sehari-hari dan tidak dapat dihindari setiap orang mengalaminya. Stres dapat memberi dampak secara total pada individu yaitu terhadap fisik, psikologis, intelektual, sosial dan spiritual serta dapat mengancam keseimbangan fisiologis (Umar dkk, 2016).

Berdasarkan hasil penelitian ini menunjukkan dari 11 responden yang mengalami stres ringan terdapat 2 responden (18,2\%) yang menderita diabetes mellitus dan dari 27 responden yang mengalami stres sedang terdapat 5 responden (18,5\%) yang menderita diabetes mellitus, sedangkan dari 57 responden yang mengalami stres berat terdapat 25 responden $(43,9 \%)$ yang menderita diabetes mellitus. Hasil uji statistik $p$-value $0,037<0,1$ sehingga $\mathrm{H}_{\mathrm{o}}$ ditolak yang berarti ada hubungan yang bermakna antara tingkat stres dengan kejadian diabetes mellitus di UPTD Diabetes Center Kota Ternate.

Dengan demikian berdasarkan hasil penelitian tentang hubungan tingkat stres dengan kejadian diabetes mellitus dapat disimpulkan bahwa responden yang sangat sering merasakan gelisah maupun tertekan dan juga menjadi marah karena emosi yang tidak dapat dikendalikan oleh diri sendiri disebabkan karena adanya suatu permasalahan yang dialami baik secara pribadi maupun bermasyarakat sebab pantangan tidak bisa mengendalikan emosi bermuara kepada stres karena kejadian DM tidak hanya berhubungan dengan makanan yang mengandung gula saja tetapi juga kondisi psikologis.

\subsubsection{Hubungan Durasi Tidur dengan Kejadian Diabetes Mellitus di UPTD Diabetes Center Kota Ternate}

Tidur merupakan kebutuhan dasar yang dibutuhkan oleh semua orang. Setiap orang memerlukan kebutuhan tidur yang cukup agar tubuh dapat berfungsi secara normal. Pada kondisi 
tidur, tubuh melakukan proses pemulihan untuk mengembalikan stamina tubuh hingga berada dalam kondisi yang optimal (Dewi dkk, 2015).

Berdasarkan hasil penelitian ini menunjukkan bahwa dari 9 responden yang mengalami durasi tidur baik tidak terdapat responden $(0,0 \%)$ yang menderita diabetes mellitus sedangkan dari 86 responden yang mengalami durasi tidur buruk terdapat 32 responden $(37,2 \%)$ yang menderita diabetes mellitus. Hasil uji statistik diperoleh $p$-value $0,025<0,1$ sehingga $\mathrm{H}_{\mathrm{o}}$ ditolak yang berarti ada hubungan yang bermakna antara durasi tidur dengan kejadian diabetes mellitus di UPTD Diabetes Center Kota Ternate.

Berdasarkan hasil penelitian ini didapatkan sebagian besar responden mengatakan bahwa waktu tidurnya di atas pukul 22:00 kemudian sering terbangun pada tengah malam dan bangun pagi hari kurang dari pukul 07:00 dan juga responden yang sebagian besar durasi tidur tidak mencapai 7 jam per malamnya mengatakan bahwa tidur siang pun tidak rutin sehingga dapat disimpulkan bahwa responden memiliki durasi tidur malam $<7$ jam per malam.

\section{PENUTUP}

\subsection{Kesimpulan}

Berdasarkan hasil penelitian dan pembahasan dapat ditarik kesimpulan sebagai berikut :

1. Tidak ada hubungan yang bermakna antara tingkat pengetahuan dengan kejadian diabetes mellitus di UPTD Diabetes Center Kota Ternate tahun 2018.

2. Ada hubungan yang bermakna antara tingkat stres dengan kejadian diabetes mellitus di UPTD Diabetes Center Kota Ternate tahun 2018.

3. Ada hubungan yang bermakna antara durasi tidur dengan kejadian diabetes mellitus di UPTD Diabetes Center Kota Ternate tahun 2018.

\subsection{Saran}

Berdasarkan hasil penelitian ini, maka saran yang dapat disampaikan adalah perlu dilakukan penelitian yang lebih mendalam tentang faktor risiko tingkat stres dan durasi tidur dengan sampel yang lebih banyak untuk bisa mengkonfirmasi hasil penelitian ini dan peneliti lain diharapkan menambah variabel yang kemungkinan berhubungan dengan kejadian diabetes mellitus yang tidak ada dalam penelitian ini.

\section{DAFTAR PUSTAKA}

Alfiani, Nurul., Hubungan Pengetahuan Diabetes Melitus Dengan Gaya Hidup Pasien Diabetes Melitus Di Rumah Sakit Tingkat Ii Dr.Soepraoen Malang tahun 2017, Nursing News Volume 2, Nomor 2, Available at: http://repository.unjaya.ac.id. (diakses pada tanggal 24 September 2018).

Azhara, Nafi., Faktor Risiko Diabetes Melitus Tipe 2 di Wilayah Kerja Puskesmas Kedungmundu Kota Semarang Tahun 2014. Universitas Dian Nuswantoro 2014, Avaliable at : http://eprints.dinus.ac.id/6655/ (diakses pada tanggal 27 Mei 2018).

Ariesiela Zita., Tasia Yenna dan Sasmita K. Poppy., Pengaruh Kurangnya Jumlah Jam Tidur Terhadap Perubahan Kadar Gula Darah Pada Mahasiswa Perklinik Fakultas Kedokteran UNIKA Atma Jaya Kota Jakarta Tahun 2014, Damianus Journal of Medicine; Vol.13 No.2 Juni 2014: hlm. 128136, Avaliable at : http://ojs.atmajaya.ac.ad (diakses pada tanggal 07 Mei 2018).

Bustan, Najib., 2015 Menejemen Pengendalian Penyakit Tidak Menular, Penerbit : Rineka Cipta, Jakarta.

Badan Penelitian dan Pengembangan Kesehatan Kementerian Kesehatan RI. Riset Kesehatan Dasar Tahun 2013, Avaliable at : http://labdatalitbangdepkes.go.id (diakses pada tanggal 2 mei 2018).

Conceicao Da Agueda., Majid Abdul dan Hutasoit Masta., Hubungan Pengetahuan Tentang Diabetes Melitus Dengan Perilaku Pencegahan Luka Pada Aktivitas Fisik Pasien Dm Tipe 2 Di Puskesmas 
Bambanglipuro Bantul Yogyakarta tahun 2011, Available at: Http://Repository.Unjaya.Ac.Id/798/ (diakses pada tanggal 24 September 2018).

Derek I. Meivy., Julia V. Rottie dan Kallo Vandri, Hubungan Tingkat Stres Dengan Kadar Gula Darah Pada Pasien Diabetes Melitus Tipe Ii Di Rumah Sakit Pancaran Kasih Gmim Manado, Fakultas Kedokteran, Universitas Sam Ratulangi Manado Tahun 2017, e-Journal Keperawatan (e-Kp) Volume 5 Nomor $1, \quad$ Available http://jurnal.stikesbethesda.ac.id/index.php/jurnalkesehatan/article/view/12 (diakses pada tanggal 24 September 2018).

Dewi Ari Pristiana., Sarfriyanda Jaka., dan Karim Darwin, Hubungan Antara Kualitas Tidur Dan Kuantitas Tidur Dengan Prestasi Belajar Mahasiswa, Program Studi Ilmu Keperawatan Universitas Riau 2016, JOM Vol. 2 No. 2, Available at: https://media.neliti.com/media/publications/185714-ID-hubungan-antara-kualitas-tidurdan-kuant.pdf (Diakses pada tanggal 11 Juli 2018).

Gunawan Nina Amelia., 2015 Kurang Tidur Bisa Sebabkan Diabetes, Available At : https://meetdoctor.com/article/awas-kurang-tidur-bisa-sebabkandiabetes\#/page/3Diabetes. (Diakses pada tanggal 24 September 2018).

Hasdiana., dan Suprapto Sentot Imam, 2014, Patologi dan Patofisiologi Penyakit, Jogja: Nuha Medika, Yogyakarta.

Irianto, Koes., 2014 Epidemiologi Penyakit Menular Dan Tidak Menular, Penerbit : Alfabeta, Bandung.

Irianto, Koes., 2014 Ilmu Kesehatan Masyarakat, Penerbit: Alfabeta, Bandung.

Izzati Wisnatul dan Nirmala., Hubungan tingkat stres dengan peningkatan kadar gula darah pada pasien diabetes mellitus di wilayah kerja puskesmas perkotaan rasimah ahmad bukittinggi tahun 2015, available at : http://ajournal.stikesyarsi.ac.id. (diakses pada tanggal 07 desember 2018).

Jacobus Danny Jaya., Gangguan Tidur Meningkatkan Risiko Diabetes Melitus tahun 2016, CDK-237/ vol. 43 no. 2, th. 2016 Avaliable at : http://www.cdkjournal.com (diakses pada tanggal 2 mei 2018).

Juddin Diah Rismayani., Hubungan Tingkat Pengetahuan Faktor Risiko Dm Dengan Status DM Pada Pegawai Negeri Sipil Uin Alauddin Makassar Tahun 2017, Available at: http://repositori.uinalauddin.ac.id/7120/1/DIAH\%20RISMAYANI\%20JUDDIN.pdf (diakses pada tanggal 24 September 2018).

Kurnia Jessy., Mulyadi dan Rottie V. Julia., Hubungan Kualitas Tidur Dengan Kadar Glukosa Darah Puasa Pada Pasien Diabetes Melitus Tipe Di Rumah Sakit Pancaran Kasih GMIM Manado tahun 2017, e-Journal Keperawatan (e-Kp) volume 5 Nomor 1, Available at:https://media.neliti.com/media/publications/105312-ID-hubungan-tingkat-stres-dengankadar-gula.pdf (diakses pada tanggal 11 Juli 2018).

Lou Peian., Zhang Pan., Zhang Lei., Chen Peipei., Chang Guiqiu., Zhang Ning., Li Ting., dan Qiao Cheng., Effects of sleep duration and sleep quality on prevalence of type 2 diabetes mellitus: A 5-year follow-up study in China 2015, diabetes esearch and clinical practice 109 (2015) 178-184, www.elsevier.com/ locate/diabres (Diakses pada tanggal 08 Desember 2018).

Mahdi Al Fadhil., Hubungan pola tidur terhadap tekanan darah pada lansia di Panti sosial tresna werdha budi sejahtera martapura, Provinsi Kalimantan Selatan Banjarmasin tahun 2016, Dinamika Kesehatan Vol. 7 No. 2, Available at: http://repository.usu.ac.id/.pdf (Diakses pada tanggal 06 Mei 2018).

Notoatmodjo, Soekidjo., 2014 Ilmu Perilaku Kesehatan, Penerbit : Rineka Cipta, Jakarta.

Perkumpulan Endokronologi Indonesia, Pengelolaan dan pencegahan Diabetes Melitus tipe 2 di Indonesia Tahun 2015, Avaliable at : http://pbperkeni.or.id/doc/konsensus.pdf (diakses pada tanggal 27 Mei 2018).

Profil Dinas Kesehatan Kota Ternate, 2017.

Profil UPTD Diabetes Center Kota Ternate 2017.

Raditya Krisna., 2016 Pengaruh Jumlah Waktu Tidur Malam Terhadap Metabolisme Tubuh, Available at: https://www.scribd.com/doc/314784710/Pengaruh-Jumlah-Waktu Tidur-Malam-TerhadapMetabolisme-Tubuh (diakses pada tanggal 26 September 2018). 
Siagian P.C. Rotua, Gambaran Tingkat Stres, Ansietas dan Depresi pada Pasien Penyakit Jantung Koroner di RSUP Haji Adam Malik Medan, Fakultas Keperawatan, Universitas Sumatera Utara, Medan, 2016, Avaliable at : http://repositori.usu.ac.id (diakses pada tanggal 10 Juli 2018).

Umar Rahmawati., Rotie V Julia., dan Lolong Jill, Hubungan Stres Dengan Citra Tubuh Pada Penderita Diabetes Melitus Tipe II Di Rumah Sakit Pancaran Kasih Gmim Manado 2016, e-journal Keperawatan (e-Kp) Volume 5 Nomor 1 Available at : https://media.neliti.com/ media/publications/ 105312-ID-hubungan-tingkat-stres-dengan-kadar-gula.pdf (diakses pada tanggal 02 Mei 2018).

Wang Louis Zizhao., Cheung Y Carol., Tapp J Robyn., Hamzah Haslina., Tan Gavin., Ting Daniel., Lamoureux Ecosse dan Wong Yin Tien., Availability and variability in guidelines on diabetic retinopathy screening in Asian countries, http://scihub.tw/http:// bjo.bmj.com/conten/101/10/1352.long Wang LZ, et al.Br J Ophthalmol 2017: 0:1-9. (diakses pada tanggal 30 April, 2018).

Waryana., 2016 Promosi Kesehatan, Penyuluhan, dan Pemberdayaan Masyarakat, Yogyakarta Penerbit: Medika Nuha.

World Health Organisation (WHO) tahun 2016. Diabetes Fakta Dan angka, http://www.searo.who.int/indonesia/topics/8-whd2016-diabetes-facts-and-numbersindonesian.pdf, availablbe at: (diakses pada tanggal 24 September 2018).

Yunir, Em., Jangan Stres Gula Darah Bisa Naik, Available at: https://lifestyle.kompas.com/ read/2014/09/26/070204523/Jangan.Stres.Gula.Darah.Bisa.Naik (diakses pada tanggal 06 september 2018). 